\title{
Adults with pulmonary arterial hypertension and congenital heart disease: When it rains, it pours
}

\section{Adultos con hipertensión arterial pulmonar y cardiopatía congénita: cuando Ilueve, diluvia}

\author{
John J. Araujo* \\ Programa de Enfermedades Cardíacas Congénitas del Adulto, Centro Cardiovascular Somer in Care, Rionegro, Colombia
}

The population of adults with congenital heart disease (ACHDs) has increased dramatically in the last few decades. Today, there are more adults than children with congenital heart disease (CHD), especially in developed countries ${ }^{1}$. A similar situation is seen in the rest of the world; in countries still lacking formal records, the population of ACHDs has been calculated according to the 2001 Bethesda conference, which estimates that there are 3,000 ACHDs for every million inhabitants ${ }^{2}$ (Figura 1). All this has happened thanks to the advances and successes in early diagnosis, pediatric cardiovascular surgery and advanced postoperative care. The change in profile of $\mathrm{CHD}$ patients had already been predicted in the 70s by Joseph $\mathrm{K}$ Perloff, who wrote "The Changing Population of CHD". This manuscript is considered the first on ACHD, and this is precisely what has occurred: ACHDs living with the residuals and sequelae of $\mathrm{CHD}^{3}$. Only simple CHDs may be considered to be cured after heart surgery; medium and high complexity CHDs are never cured, they are actually repaired. The residuals and sequelae will continue to evolve throughout adulthood, manifesting mainly as arrhythmias, heart failure, syncope, aortic dissection, endocarditis, thromboembolism, bleeding, aortic aneurysm, pulmonary arterial hypertension (PAH), and sudden cardiac death, and may take decades to appear. Sixty percent of CHDs are diagnosed and treated in the first year of life, and $30 \%$ throughout childhood and adolescence up to 16 years of age. It is estimated that $10 \%$ are diagnosed in adulthood. As de result this, the current ACHD population is split into two groups: 1- newly diagnosed ACHDs; this population only makes up $10 \%$ of cases, and they are individuals who were never diagnosed or treated in childhood or adolescence but have survived beyond 18 years of age. They have had a natural survival, with all the resulting hemodynamic sequelae (heart failure [HF], PAH, arrhythmias, among others); and 2- ACHDs who underwent surgery in childhood or adolescence; these make up $90 \%$ of cases. Most of these patients (85\%) have medium and high complexity CHD according to the 2001 Bethesda classification, and this is the group which will grow the most over the next 10-20 years ${ }^{4}$. A dreaded complication in both unrepaired $\mathrm{CHD}$ and $\mathrm{CHD}$ with delayed repair is the development of $\mathrm{PAH}$, which happens in $4-6 \%$ of all $\mathrm{ACHDs}^{5}$. The development of $\mathrm{PAH}$ depends on the size of the defect, its location (pre-tricuspid, post-tricuspid) and the time elapsed. According to the $6^{\text {th }}$ World Symposium on Pulmonary Hypertension $(\mathrm{WSPH})^{6}$, hemodynamic definitions of pulmonary hypertension $(\mathrm{PH})$ measured by right heart
Correspondencia:

John J. Araujo

E-mail: johnjairoaraujo@gmail.com

DOI: 10.24875/ACME.M20000145
Disponible en internet: $10-02-2020$ Arch Cardiol Mex. 2020;90(3):336-338 www.archivoscardiologia.com BY-NC-ND (http://creativecommons.org/licenses/by-nc-nd/4.0/). 


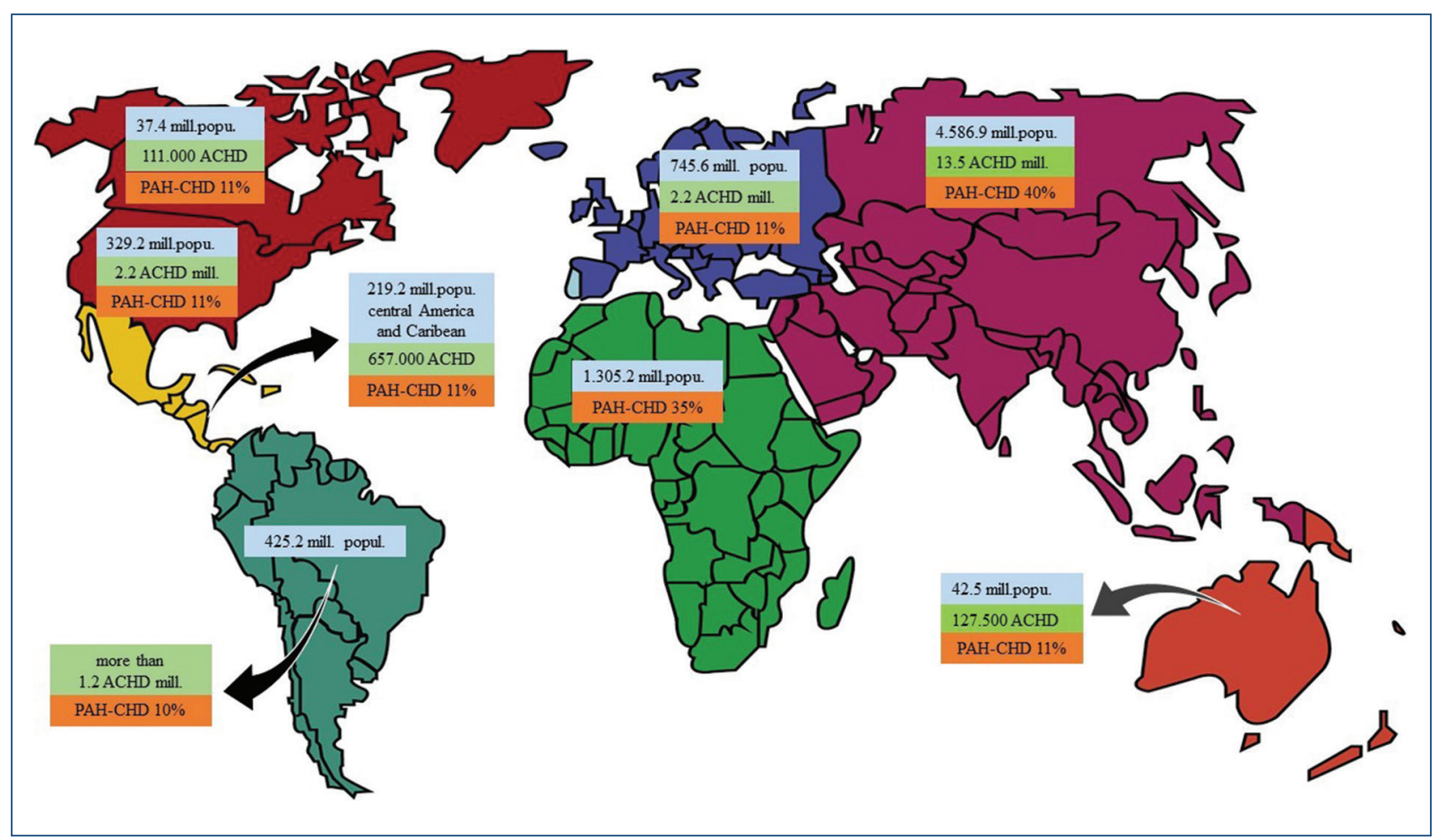

Figura 1. Worldwide population mid 2019: 7,691,5 millions ${ }^{7}$.

Worldwide population mid at 2019, distributed on five continents, differentiated in America (Canada, USA, Central and South America).

Current estimate population of adults with congenital heart disease living around the world (except in Africa, due to poor register).

Global distribution of estimated prevalence pulmonary arterial hypertension due congenital heart disease, differentiated in America (Canada, USA, Central and South America).

ACHD: Adult Congenital Heart Disease; Mill.: millions; Popu.: population; PAH: Pulmonary Arterial Hypertension.

catheterization include: mean pulmonary arterial pressure $(\mathrm{mPAP})>20 \mathrm{mmHg}$, pulmonary arterial wedge pressure $(\mathrm{PAWP}) \leq 15 \mathrm{mmHg}$, and pulmonary vascular resistance $(P V R) \geq 3$ Wood units $(\mathrm{WU})$. This is the pure precapillary form, and includes groups 1, 3, 4 and 5 of the Nice classification. If the mPAP $>20 \mathrm{mmHg}$, PAWP $>15 \mathrm{mmHg}$ and PVR $<3 \mathrm{WU}$, it is the isolated post-capillary form of $\mathrm{PH}$ and includes groups 2 and 5 too; and if the mPAP $>20 \mathrm{mmHg}$, PAWP $>15 \mathrm{mmHg}$ and PVR $\geq 3 \mathrm{WU}$, it is the combined pre- and post-capillary form and includes groups 2 and 5. CHD make up 3 of five groups (1, 2 and 5). In 2019, the global population was 7.6 billion $^{7}$, and at the same time there were approximately 50 million ACHDs worldwide and the estimated global prevalence of $\mathrm{PH}$ due to $\mathrm{CHD}$ was estimated at about 25 people per million in the general population. Therefore, there could be $1.250 \mathrm{ca}-$ ses of PH due CHD. Eighty percent of patients with $\mathrm{PH}$ live in developing countries and in this population, $\mathrm{CHDs}$ are a significant cause of $\mathrm{PH}$ in low income countries (Figura 1) $)^{8}$. The phrase "when it rains it pours" refers to the fact that the ACHD population affected by PAH has never really been well. For ACHDs with increased pulmonary flow (large VSDs, conotruncal defects without pulmonary stenosis, single ventricle, among others) who were not repaired in childhood, had serious symptoms (HF, repetitive pneumonias, growth failure, cyanosis, among others) and currently have serious CHD sequelae combined with the most extreme form of PAH (Eisenmenger syndrome, commonly manifested in chronic hypoxemia with multiple associated systemic complications), their mortality rate increases 12.8 times compared to the general population, and sudden death has been reported at about $9 \%{ }^{9}$.

On the other hand we have complex ACHDs who were repaired during childhood or adolescence. Many have residuals and sequelae today, with frequent relapses and hospitalizations. Depending on the severity, some develop early or late PAH (postoperative 
$\mathrm{PAH})$, suffering the inherent symptoms of their CHD with the addition of PAH symptoms which markedly affect their quality of life and functional class. Recently, the new 2018 AHA/ACC - ACHD guidelines have developed the anatomical and physiological (AP) classification ${ }^{10}$ which integrates the anatomical or morphological parts of the repaired or unrepaired $\mathrm{CHD}$ with the New York Heart Association (NYHA) functional class and nine clinical variables (hypoxemia, pulmonary hypertension/pulmonary arterial hypertension, hemodynamically significant shunt, venous and arterial stenosis, exercise capacity, end-organ dysfunction, concomitant acquired valve disease, arrhythmia, and aortopathy) which, if present, increase the severity of the CHD. The classification establishes four physiological stages (from lesser to greater severity: A-D). The ACHDs with PAH are considered to be the highest risk group in the classification (category $D$ ). Patients with $\mathrm{CHD}$ associated with $\mathrm{PAH}$, compared to patients with $\mathrm{CHD}$ without $\mathrm{PAH}$, are more symptomatic and have at least a doubled mortality risk. With the exception of some PAH cases from group 4 (chronic pulmonary thromboembolic disease), they are cured. The rest of the forms of PAH are not cured; they are stabilized with pulmonary vasodilators, most of which are high cost medications (endothelin receptor antagonists and prostanoids, among others) for medium and low-income countries. In conclusion, moderate and high complexity CHDs, which are not cured, added to the also incurable PAH are a very bad combination; indeed, when it rains it pours.

\section{Conflicts of Interest}

None.

\section{Funding}

None.

\section{Ethical disclosures}

Protection of human and animal subjects. The authors declare that no experiments were performed on humans or animals for this study.

Confidentiality of data. The authors declare that no patient data appear in this article.

Right to privacy and informed consent. The authors declare that no patient data appear in this article.

\section{References}

1. Gilboa S, Devine O, Kucik J, Oster M, Riehle-Colarusso T, Nembhard W, et al. Congenital heart defects in the United States estimating the magnitude of the affected population in 2010. Circulation. 2016; 134:101-9.

2. Weeb, G. \& Williams, R. $32^{\text {nd }}$ Bethesda conference: care of the adult with congenital heart disease. J Am Coll Cardiol. 2001; 37(5), 1161-98.

3. Perloff JK. Pediatric congenital cardiac becomes a postoperative adultthe changing population of congenital heart disease. Circulation. 1973; 47: 606-19.

4. Araujo JJ. The Profile of an Adult with Congenital Heart Disease. Int J Clin Cardiol.2018; 5:131.

5. Duff els M, Engelfriet $P$, Berger R, van Loon R, Hoendermis E, Vriend J, et al. Pulmonary arterial hypertension in congenital heart disease: an epidemiologic perspective from a Dutch registry. Int J Cardiol 2007; 120: 198-204.

6. Simonneau G, Montani D, Celermajer DS, Denton C, Gatzoulis M, Krowka M, et al. Haemodynamic definitions and updated clinical classification of pulmonary hypertension. Eur Respir J. 2019; 53(1):1801913.

7. Populatin Wordl (Internet) https://www.prb.org/2018-world-population-data-sheet-with-focus-on-changing-age-structures/

8. Hoeper M, Humbert M, Souza R, Idrees M, Kawut S, Sliwa-Hahnle K, et al. A global view of pulmonary hypertension. The Lancet. Respiratory Medicine. 2016, 4(4):306-22.

9. Gonzalez R, Lopez C, Subirana M, Ruíz J, González I, Cubero J, et al Pulmonary hypertension and congenital heart disease: An insight from the REHAP national registry. Int J Cardiol. 2015; 184: 717-23.

10. Stout K, Daniels C, Aboulhosn J, Bozkurt B, Broberg C, Colman J, et al. 2018 AHA/ACC Guideline for the management of adults with congenital heart disease: executive summary: a report of the American College of Cardiology/American Heart Association Task force on clinical practice guidelines. J Am Coll Cardiol. 2019; 73 (12):1494-63. 